\title{
Origin of Enhanced Electricity Generation on Magnéli Phase Titanium Suboxide Nanocrystal Film
}

Pengchao Si, ${ }^{\dagger}+$ Mengqi Li,${ }^{\dagger}$ Xiang Wang, ${ }^{\dagger}$ Feifei Sun, ${ }^{\dagger}$ Jingjing Liu, ${ }^{\dagger}$ Qinhuan

Wang, ${ }^{\dagger}$ Fuqiang Ren, ${ }^{\dagger}$ Haoran Kong, ${ }^{\dagger}, \dot{t}$ and $Y u$ Wang $^{* \dagger}$

$\dagger$ State Key Laboratory of Multiphase Complex Systems, Institute of Process

Engineering, Chinese Academy of Sciences, Beijing 100190, P. R. China

+ School of Chemical Engineering, University of Chinese Academy of Sciences,

Beijing 100049, P. R. China

*Corresponding author. E-mail: wyu@ipe.ac.cn. 
Contents

1. Element composition and its corresponding quantitative relationship of $\mathrm{Ti}_{3} \mathrm{C}_{2} \mathrm{~T}_{\mathrm{x}}$.

2. Element composition and its corresponding quantitative relationship of freeze-dried PTA gel.

3. Digital photos of three different concentrations of PTA gels over time.

4. Optical image of a thin film prepared by high viscosity R500.

5. Schematic diagram of test method for hydrovoltaic performance of Magnéli phase Film.

6. The i-t curves of T800, T900 and T1000 at a constant voltage of $1 \mathrm{~V}$.

7. The measured $\mathrm{V}_{\mathrm{OC}}$ at 126,246 , and 366 hours after sample T1000 preparation.

8. Resistance test results and $\mathrm{V}_{\mathrm{OC}}$ test results for films of different thickness.

9. XPS survey spectra of T800, T900 and T1000.

10. High-resolution Ti $2 p$ spectra of T800, T900 and T1000.

11. The $\mathrm{V}_{\mathrm{OC}}$ of the film tested in six different concentrations of $\mathrm{NaCl}$.

12. The $\mathrm{V}_{\mathrm{OC}}$ of the film tested in $\mathrm{HCl}$ solutions with different $\mathrm{pH}$.

13. The measured $\mathrm{V}_{\mathrm{OC}}$ of the film tested at different flow rate. 
1. Element composition and its corresponding quantitative relationship of $\mathrm{Ti}_{3} \mathrm{C}_{2} \mathrm{~T}_{\mathrm{x}}$.
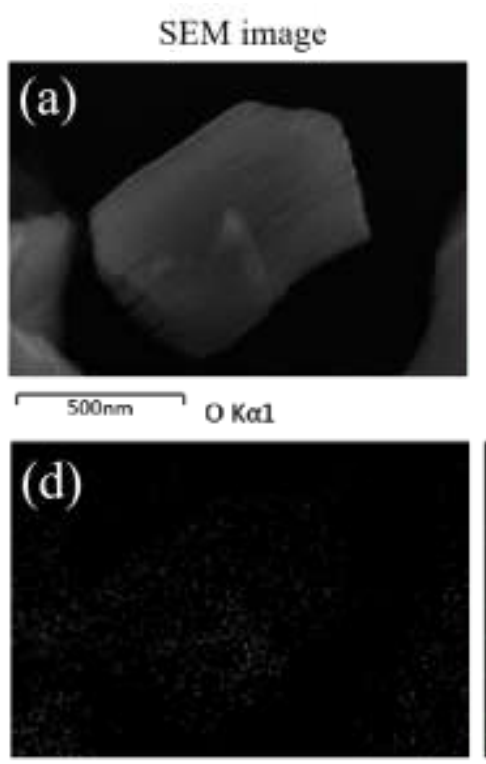

5
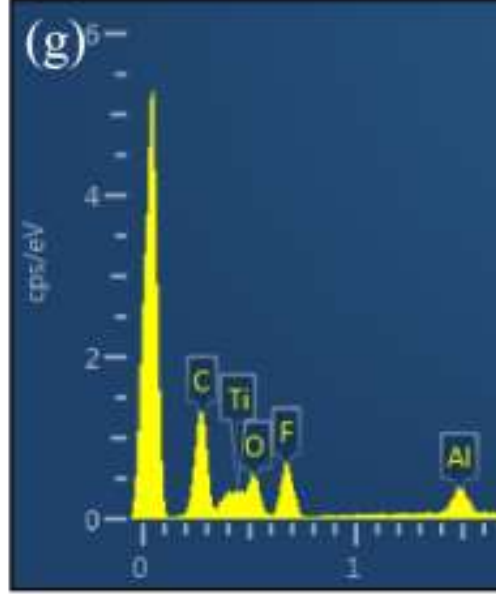

C K $\alpha 12$
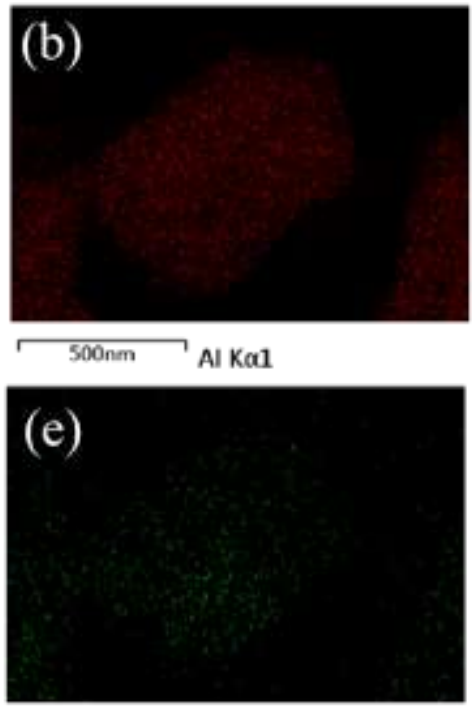

$500 \mathrm{~nm}$
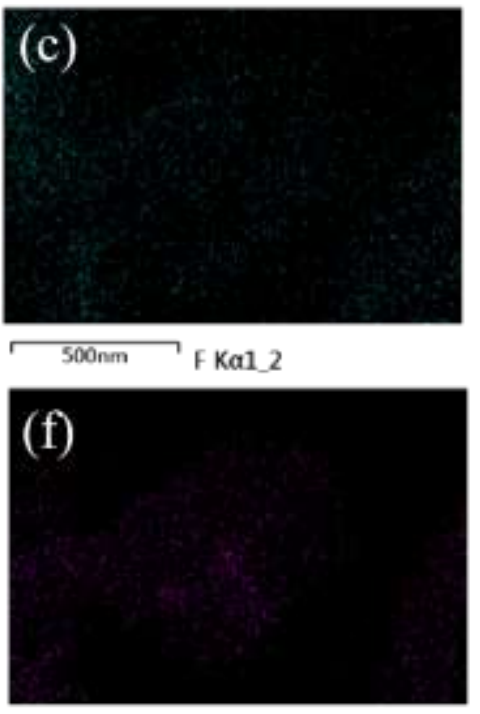

$500 \mathrm{~nm}$

Figure S1. Element mapping (a-f) and corresponding quantitative analysis (g) of MXene obtained by EDX. 
2. Element composition and its corresponding quantitative relationship of freeze-dried PTA gel.

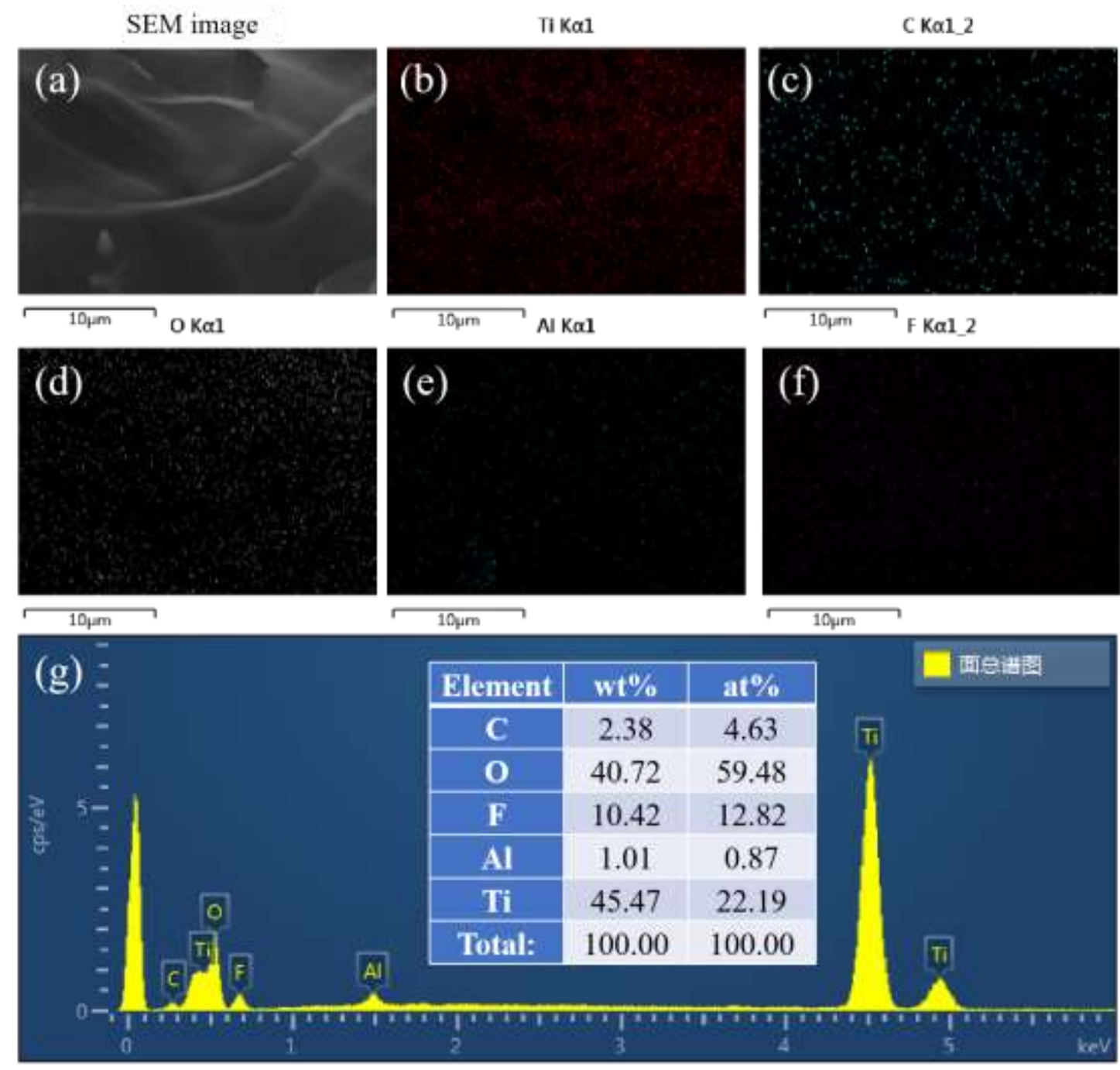

Figure S2. Element mapping (a-f) and corresponding quantitative analysis

(g) of freeze-dried PTA gel obtained by EDX. 
3. Digital photos of three different concentrations of PTA gels over time.

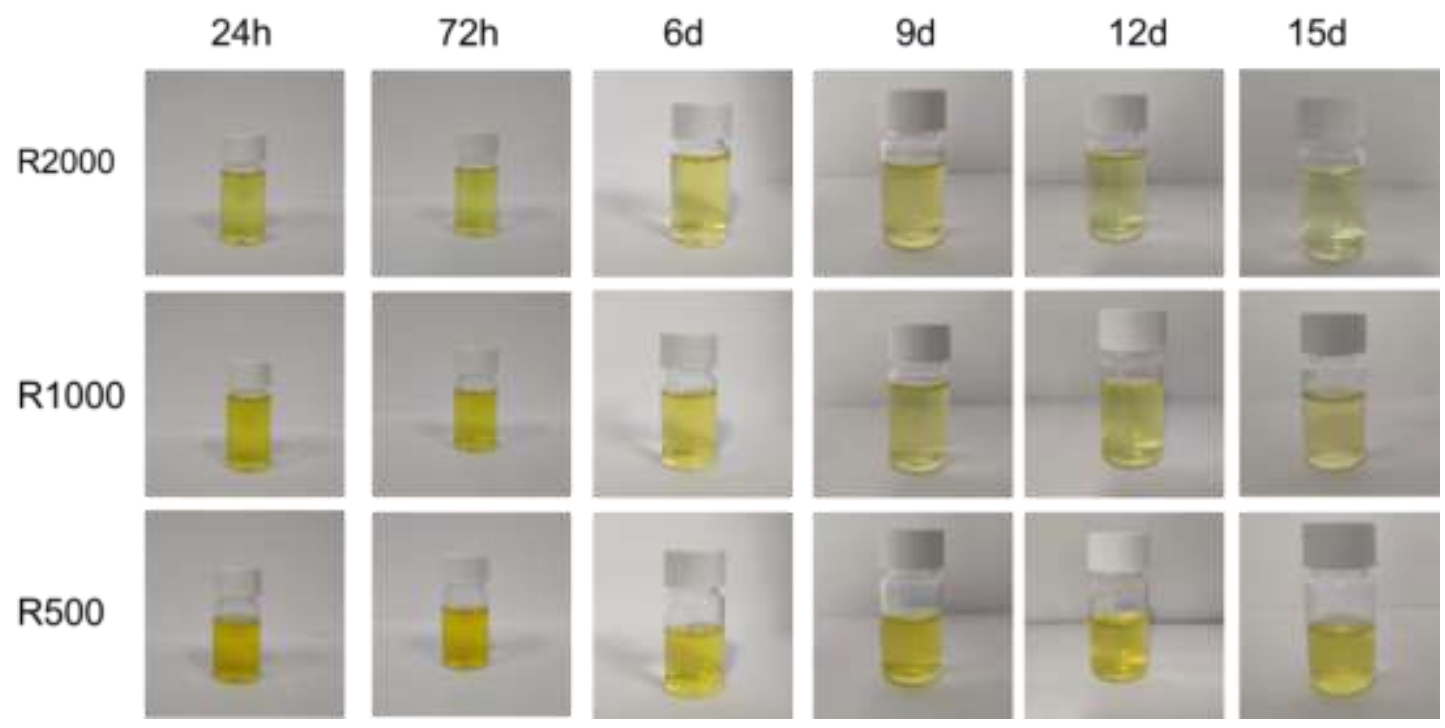

Figure S3. Appearance changes of R500, R1000 and R2000 over time. 
4. Optical image of film prepared by high viscosity R500.

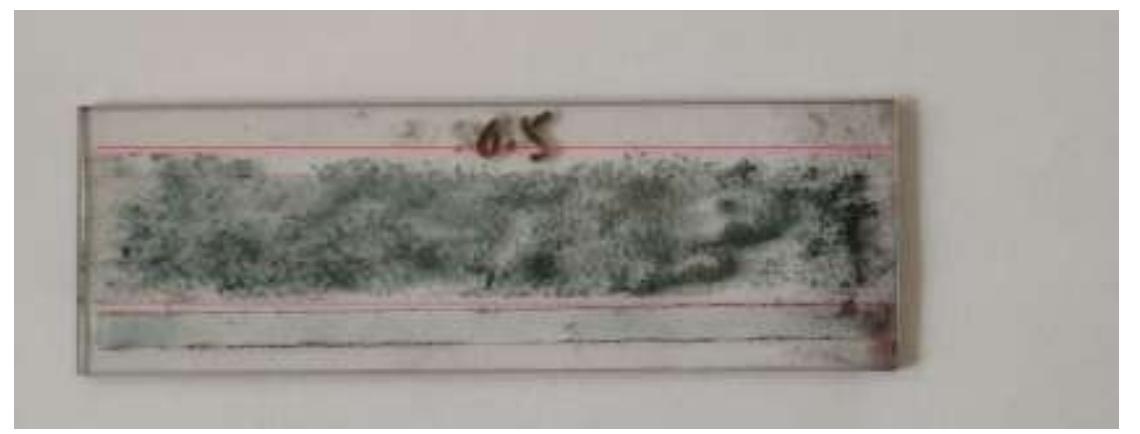

Figure S4. Optical image of film prepared by high viscosity R500. 
5. The test method for hydrovoltaic performance of Magnéli phase Film.

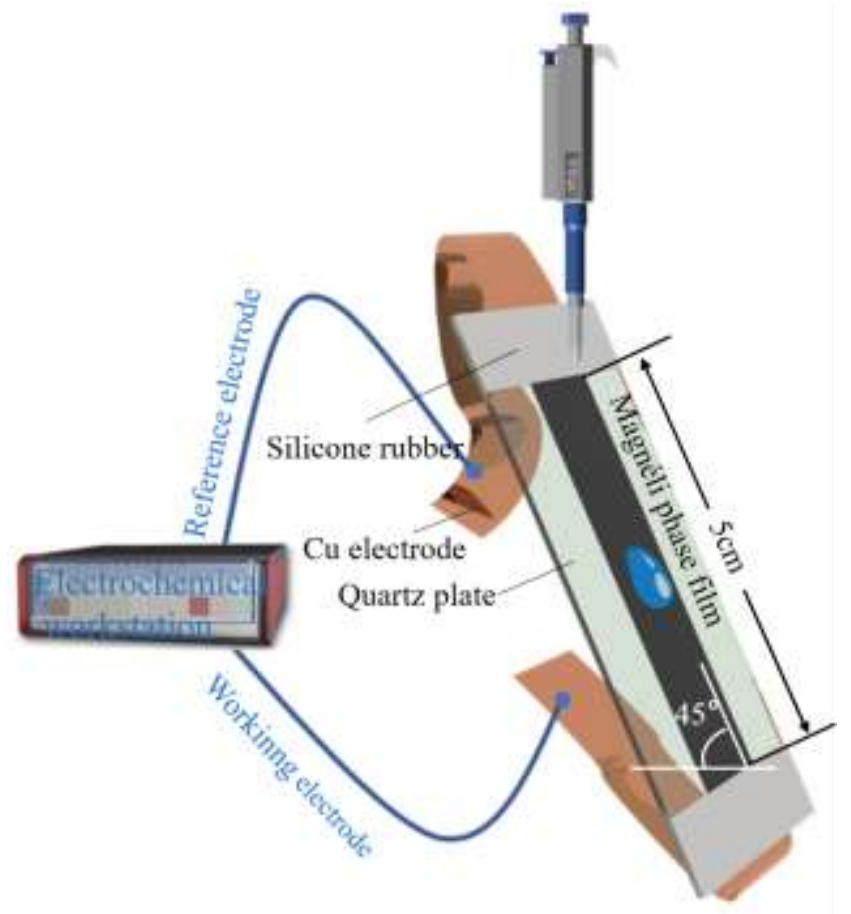

Figure S5. Schematic diagram of test method for hydrovoltaic performance of Magnéli phase Film. 
6. The i-t curves of T800, T900 and T1000 at a constant voltage of $1 \mathrm{~V}$.

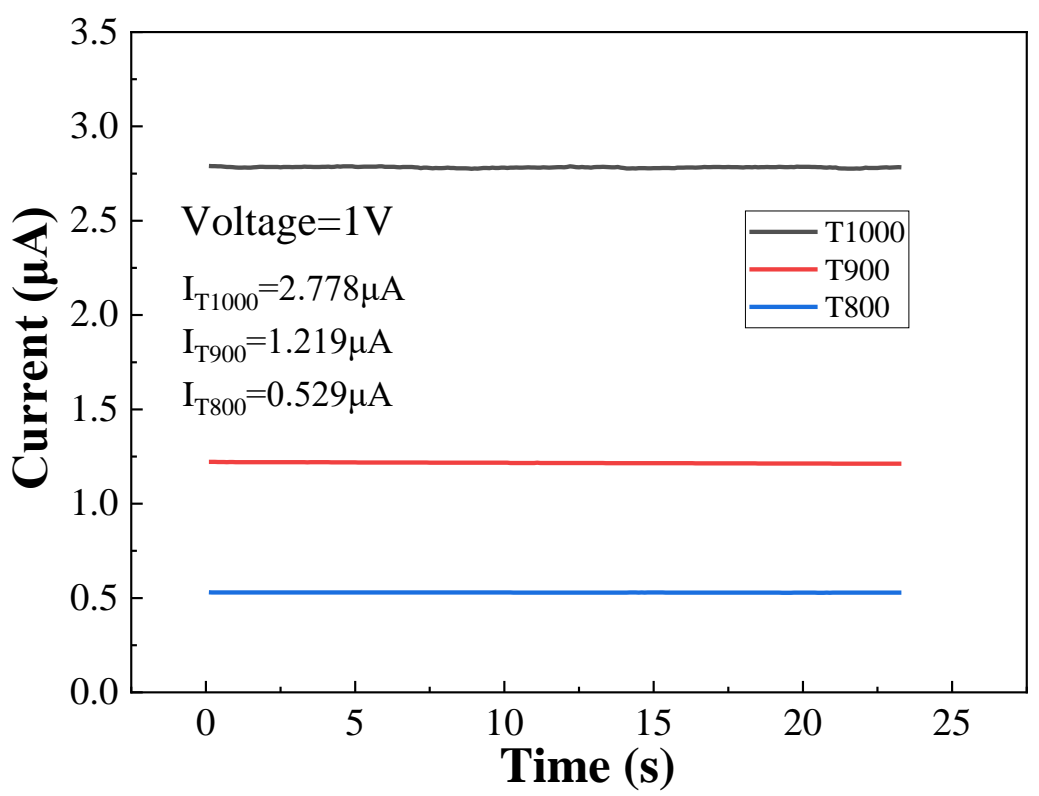

Figure S6. The i-t curves of T800, T900 and T1000 at a constant voltage of $1 \mathrm{~V}$.

At $1 \mathrm{~V}$, the current of $\mathrm{T} 800$, $\mathrm{T} 900$ and $\mathrm{T} 1000$ is $0.529,1.219,2.778 \mu \mathrm{A}$, respectively. Therefore, the resistances of T800, T900 and T1000 can be calculated as $1.89,0.82$ and $0.36 \mathrm{M} \Omega$. 
7. The measured $V_{O C}$ at 126,246 , and 366 hours after sample T1000 preparation.

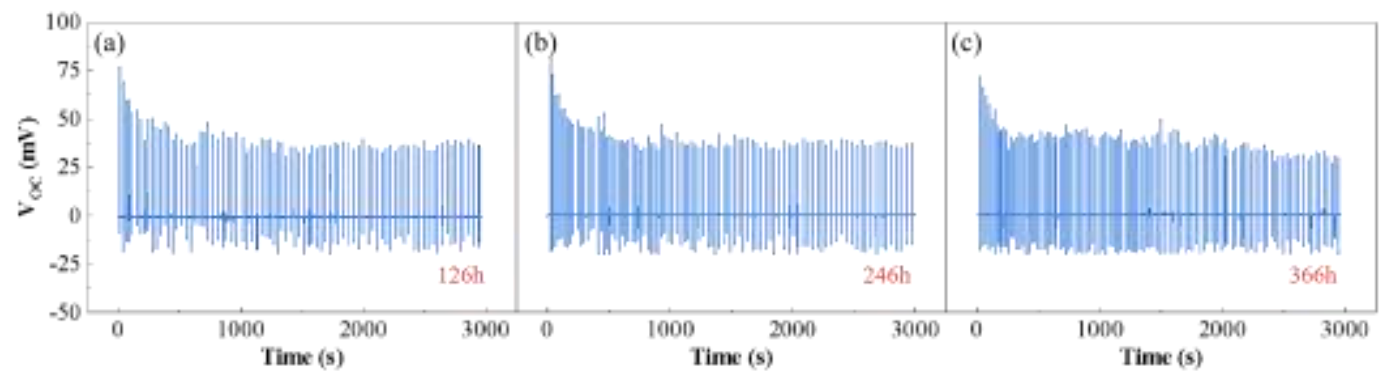

Figure S7. The measured $\mathrm{V}_{\mathrm{OC}}$ at 126 (a), 246 (b), and 366 (c) hours after sample T1000 preparation. 
8. Resistance tests and $\mathrm{V}_{\mathrm{OC}}$ tests for films of different thickness.
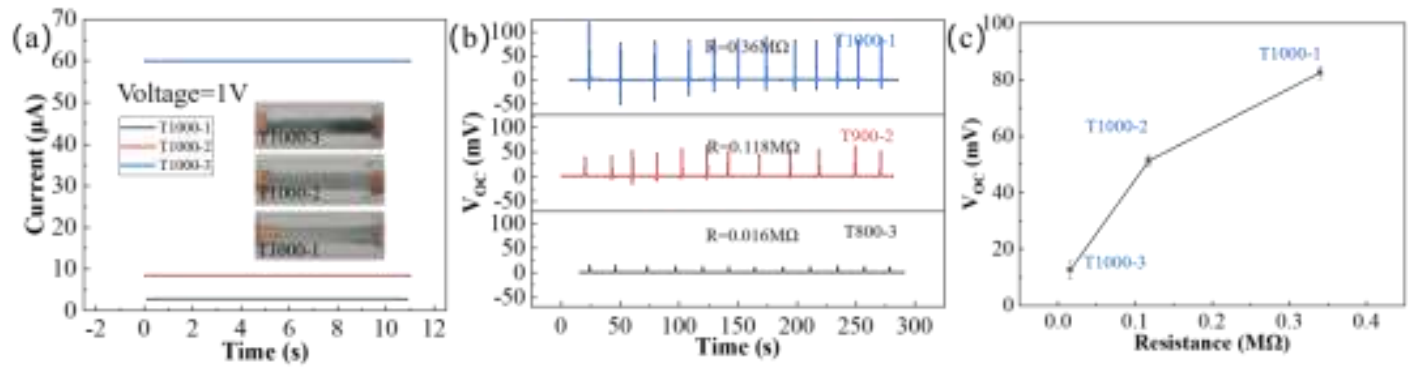

Figure S8. a) Current of samples T1000-1, T1000-2 and T1000-3 at a bias voltage of $1 \mathrm{~V} . \mathrm{b}$ ) The measured $\mathrm{V}_{\mathrm{OC}}$ of samples $\mathrm{T} 1000-1, \mathrm{~T} 1000-2$ and T1000-3. c) The measured $\mathrm{V}_{\mathrm{OC}}$ as a function versus resistance.

At a bias of 1 volt, the current of samples T1000-1, T1000-2, and T10003 are $2.778,8.2003$ and $60.116 \mu \mathrm{A}$ (Figure S6 a), respectively, so the calculated resistances are $0.360,0.118$ and $0.016 \mathrm{M} \Omega$. 
9. XPS survey spectra of T800, T900 and T1000.

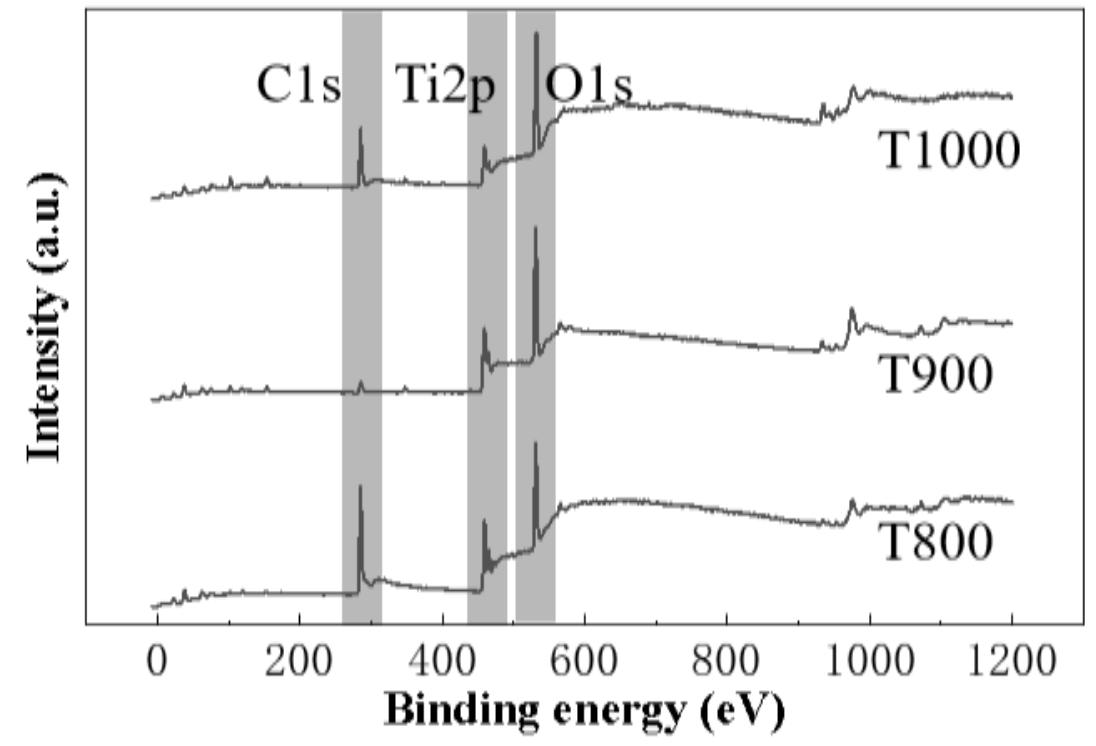

Figure S9. XPS survey spectra of T800, T900 and T1000. 
10. High-resolution Ti 2p spectra of T800, T900 and T1000.

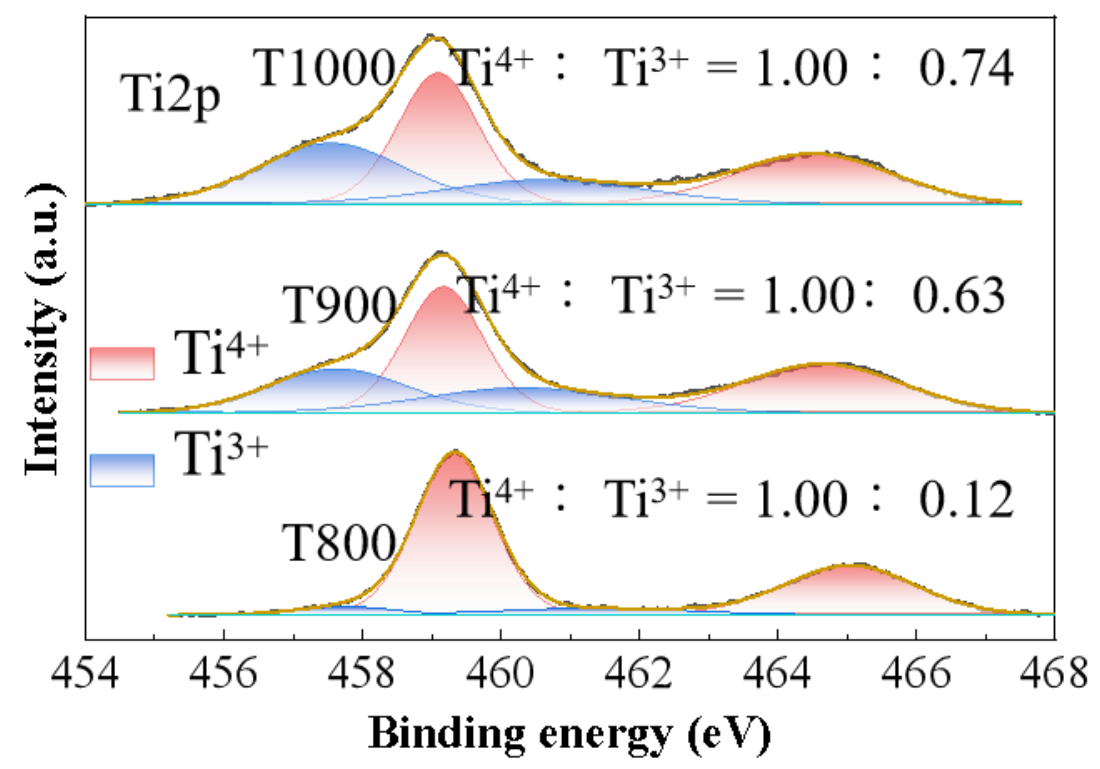

Figure S10. High-resolution Ti 2p spectra of T800, T900 and T1000. 
11. The measured $\mathrm{V}_{\mathrm{OC}}$ of the film tested in six different concentrations of $\mathrm{NaCl}$.
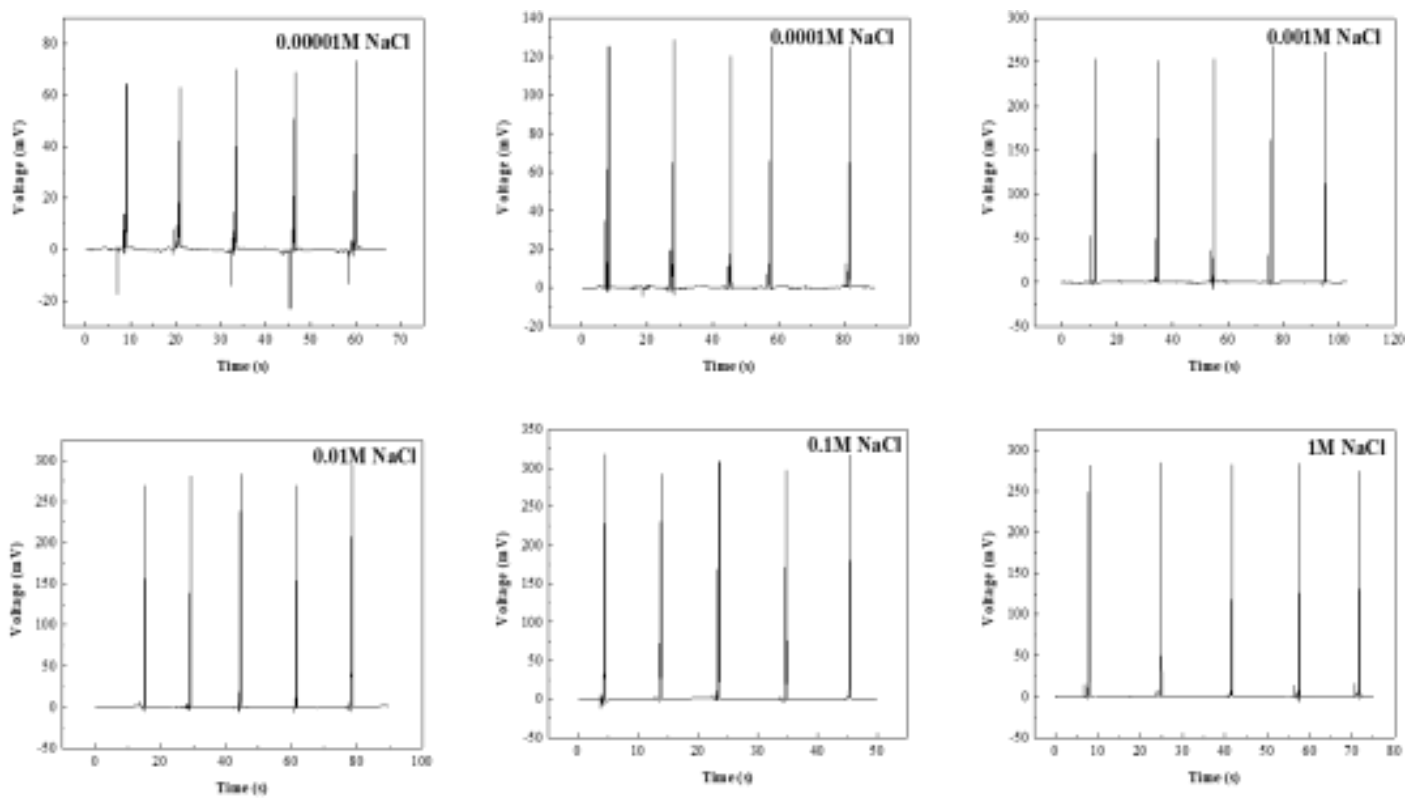

Figure $\mathrm{S} 11$. The measured $\mathrm{V}_{\mathrm{OC}}$ by stimulate the Magnéli phase film with 1, $0.1,0.01,0.001,0.0001$ and $0.00001 \mathrm{M} \mathrm{NaCl}$. 
12. The measured $\mathrm{V}_{\mathrm{OC}}$ of the film tested in different $\mathrm{pH}$ value.
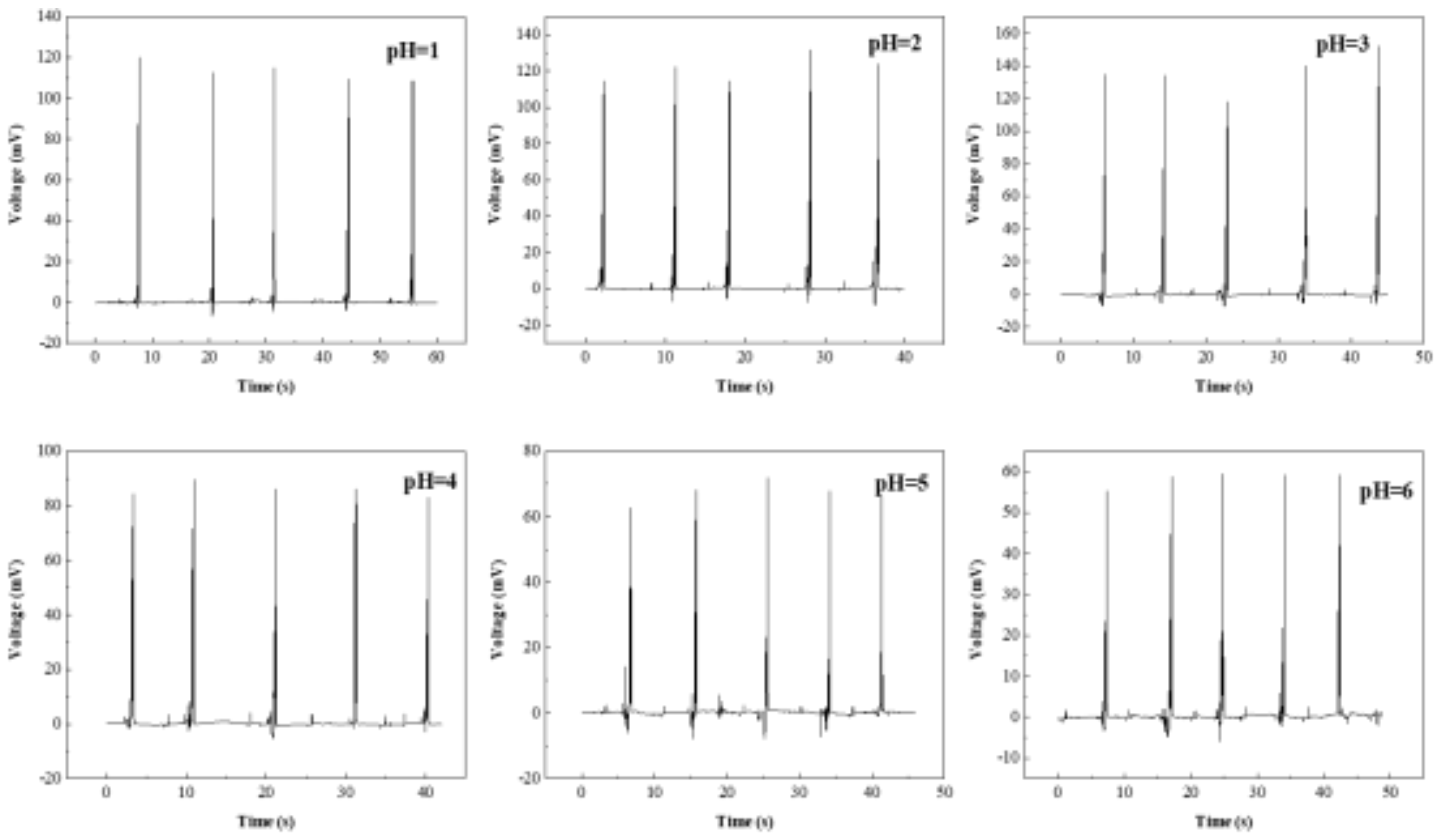

Figure $\mathrm{S} 12$. The measured $\mathrm{V}_{\mathrm{OC}}$ by stimulate the Magnéli phase film with $\mathrm{pH}=1,2,3,4,5,6$. 
13. The measured $\mathrm{V}_{\mathrm{OC}}$ of the film tested at different flow rate.

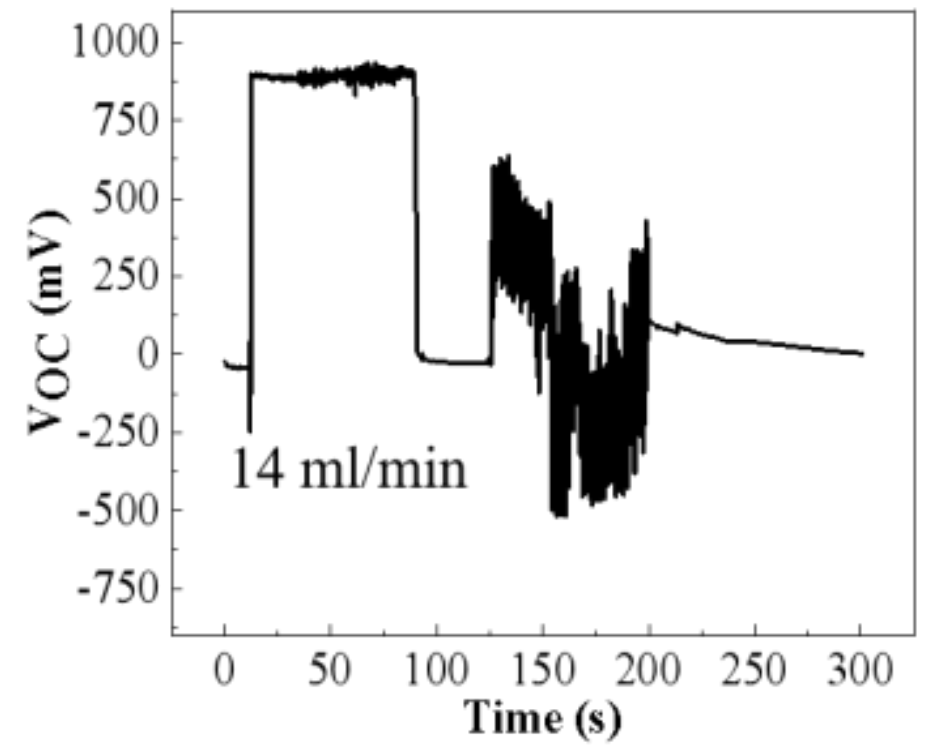

Figure $\mathrm{S} 13$. The $\mathrm{V}_{\mathrm{OC}}$ generated by the flexible film at $14 \mathrm{~mL} / \mathrm{min}$ and higher flow rates. 